\title{
ARTIGO - FORMAÇÃO DE EDUCADORASIES, DIVERSIDADE E COMPROMISSO SOCIAL
}

\author{
JÚLIO EMÍLIO DINIZ-PEREIRA '* \\ ORCID: https://orcid.org/0000-0002-5401-4788 \\ LEÔNCIO JOSÉ GOMES SOARES ${ }^{* *}$ \\ ORCID: https://orcid.org/ 0000-0003-4750-2529
}

RESUMO: O título deste artigo foi o "tema gerador" central do $2^{\circ}$ Congresso Internacional Paulo Freire: O Legado Global. Nele, os autores partem de uma breve análise sobre a racionalidade crítica na formação de educadoras/ es como alternativa às chamadas visões técnica e prática na preparação de novas/os profissionais da educação para, em seguida, apresentarem uma discussão mais teórica e conceitual sobre as diferenças entre os termos "formação de professores para a justiça social", comum em países como os Estados Unidos, e "formação de educadoras/es por meio da transformação social" - a expressão defendida neste texto. A partir daí, eles discutem algumas características que não poderiam faltar em um programa de formação de educadoras/es por meio da transformação social para, no fim, analisar uma experiência concreta de formação orientada por meio da transformação social: a experiência do Movimento dos Trabalhadores Sem Terra, no Brasil, na década de 1990 e início dos anos 2000.

Palavras-chave: Formação de educadoras/es. Racionalidade crítica. Transformação social. MST.

\section{ARTICLE - TEACHER EDUCATION, DIVERSITY AND SOCIAL COMMITMENT}

ABSTRACT: The title of this paper has been the "generative theme" of the $2^{\text {nd }}$ International Conference Paulo Freire: The Global Legacy. In this paper, the authors start from a brief analysis of critical rationality in teacher education as an alternative to the so-called technical and practical views in the preparation of new teachers, and then they present a more theoretical and conceptual discussion about the differences between the terms "teacher

'Universidade Federal de Minas Gerais, Programa de Pós-graduação em Educação, Belo Horizonte, MG, Brasil.

"Doutor em Educação pela University of Wisconsin, em Madison, nos Estados Unidos. Professor do Programa de Pós-graduação em Educação da Universidade Federal de Minas Gerais (PPGE/FaE/UFMG). Bolsista de Produtividade em Pesquisa do CNPq - Nível 2. E-mail:< juliodiniz@ufmg.br > .

"* Doutor em Educação pela Universidade de São Paulo (USP). Professor do Programa de Pós-graduação em Educação da Universidade Federal de Minas Gerais (PPGE/FaE/UFMG). Bolsista de Produtividade em Pesquisa do CNPq - Nível 2. E-mail:<leonciosoares@uol.com.br > . 
education for social justice," popular in countries such as the United States, and "teacher education through social transformation" - the term the authors defend in this paper. From there, they discuss some characteristics that should not be lacking in a teacher education program through social transformation, to analyze a concrete experience of this type of teacher education: the experience that came from the Movimento dos Trabalhadores Sem Terra, in Brazil, in the 1990's and in the beginning of the 2000's.

Keywords: Teacher education. Critical rationality. Social transformation. MST.

\section{INTRODUÇã̃o}

"Formação de educadoras/es, diversidade e compromisso social" foi o "tema gerador" central do $2^{\circ}$ Congresso Internacional Paulo Freire: O Legado Global, realizado na Universidade Federal de Minas Gerais (UFMG), em Belo Horizonte, entre os dias 29 de abril a $1^{\circ}$ de maio de 2018. Nós, autores deste texto, estivemos diretamente envolvidos na organização desse evento na capital mineira.

Neste artigo, partimos de uma breve análise sobre a racionalidade crítica na formação de educadoras $/$ es $^{1}$ como alternativa às chamadas visões técnica e prática na preparação de novas/os profissionais da educação para, em seguida, apresentarmos uma discussão mais teórica e conceitual sobre as diferenças entre os termos "formação de professores para a justiça social", comum em países como os Estados Unidos, e "formação de educadoras/es por meio da transformação social" - a expressão que defendemos neste texto. A partir daí, discutimos algumas características que não poderiam faltar em um programa de formação de educadoras/es por meio da transformação social para, no fim, analisar uma experiência concreta de formação orientada por meio da transformação social: a experiência do Movimento dos Trabalhadores Sem Terra, no Brasil, na década de 1990 e no início dos anos 2000.

\section{RACIONALIDADE CRÍTICA DE FORMACุÃO DOCENTE}

No campo da pesquisa sobre formação de professores, discutemse hoje, no mínimo, três racionalidades que, conscientes ou não, orientam modelos e programas de formação docente no Brasil e no mundo.

Os modelos mais difundidos de formação de professores são aqueles orientados pela racionalidade técnica. De acordo com 
esse modelo, também conhecido como a epistemologia positivista da prática, "a atividade profissional consiste na solução instrumental de um problema feita pela rigorosa aplicação de uma teoria científica ou uma técnica" (SCHÖN 1983, p. 21). Segundo a racionalidade técnica, o professor é visto como um técnico, um especialista que rigorosamente põe em prática as regras científicas e/ou pedagógicas. Assim, para se preparar o profissional da educação, conteúdo científico e/ou pedagógico é necessário, o qual servirá de apoio para sua prática. Durante a prática, professores devem aplicar - reforçase aqui a visão aplicacionista da relação entre teoria e prática - tais conhecimentos e habilidades científicos e/ou pedagógicos.

Em diferentes países do mundo, mesmo considerando algumas variações, a maioria dos currículos de formação de professores é construída de acordo com o modelo da racionalidade técnica. Instituições internacionais de fomento, tais como o Banco Mundial (BM), são as principais responsáveis pela promoção de reformas conservadoras em programas de formação de professores, especialmente em países em desenvolvimento. ${ }^{2}$ Certamente, o Banco Mundial (BM) tem sido um dos mais importantes veículos de divulgação da racionalidade técnica e científica em reformas educacionais e, mais especificamente, em reformas de programas de formação de professores no mundo.

Discussões mais atuais sobre a carreira docente enfatizam a complexidade dessa profissão, que envolve conhecimento teórico e prático, marcada pela incerteza e brevidade de suas ações. Os professores têm sido vistos como profissionais que refletem, questionam e constantemente examinam suas práticas pedagógicas cotidianas, as quais, por sua vez, não estão limitadas ao chão da escola.

Para a racionalidade prática, "a prática não pode ser reduzida ao controle técnico" (CARR e KEMMIS: 1986, p. 36). Assim, o conhecimento dos profissionais não pode ser visto como um conjunto de técnicas ou como um kit de ferramentas para a produção da aprendizagem. O julgamento profissional é, portanto, "guiado por critérios advindos do processo por si mesmo, ou seja, critérios baseados na experiência e aprendizagem os quais distinguem processos educacionais de não-educacionais e os quais separam as boas práticas das indiferentes ou ruins" (CARR e KEMMIS: 1986, p. 37).

A racionalidade prática procura, então, superar as barreiras colocadas pelo modelo positivista de formação de professores. De fato, novas formas de pensar a formação de professores tentam romper com concepções tradicionais e dominantes na formação docente. 
Contudo, já existem sinais de que a pesquisa-ação tem sido "raptada" a serviço da racionalidade técnica (ELLIOT, 1991). Organizações internacionais conservadoras, incluindo o Banco Mundial (BM), têm recentemente se apropriado do discurso da racionalidade prática para manter seu controle sobre os programas de formação de professores.

Finalmente, o livro de Carr e Kemmis, Becoming Critical: Education, Knowledge and Action Research, baseado na Teoria Crítica (Escola de Frankfurt) e na ciência sócio-crítica de Habermas, apresenta uma visão diferente da relação teoria-prática - uma visão crítica, em que o principal objetivo é a transformação da educação e da sociedade.

De acordo com Carr e Kemmis (1986), as visões técnica e prática não são muito distintas no que tange à educação. "De um lado, professores desejam enfatizar os objetivos complexos da educação contemporânea, os quais requerem habilidades sofisticadas e conhecimento técnico sobre métodos de ensino. De outro, eles querem enfatizar sua autonomia como profissionais, o que requer deliberação prática" (p. 38). Ainda nas palavras desses autores,

Enquanto os pesquisadores positivistas da educação podem frequentemente ser descritos como "objetivistas", enfatizando a natureza objetiva do conhecimento como independente do observador, e pesquisadores interpretativistas da educação podem ser descritos como "subjetivistas", enfatizando a compreensão subjetiva do ator como base para a interpretação da realidade social, pesquisadores críticos da educação, incluindo aqueles que atuam na pesquisa-ação, adotam uma visão de racionalidade dialética. Portanto, (...) tais pesquisadores tentam descobrir como situações são forjadas por condições "objetivas" e "subjetivas" e procuram explorar como tais tipos de condições podem ser transformadas (p. 183).

$\mathrm{Na}$ racionalidade crítica, a educação é "historicamente localizada" - ela acontece contra um pano de fundo sócio-histórico e projeta uma visão do tipo de futuro que nós esperamos construir -, uma atividade social - com consequências sociais, não apenas uma questão de desenvolvimento individual -intrinsecamente política afetando as escolhas de vida daqueles envolvidos no processo - e finalmente, problemática - "seu propósito, a situação social que ele modela ou sugere, o caminho que ele cria ou determina relações entre os participantes, o tipo de meio no qual ele trabalha e o tipo de conhecimento para o qual ele dá forma" (CARR e KEMMIS: 1986, p. 39). Ainda segundo os autores:

Ela carrega uma visão de pesquisa educacional como análise crítica que direciona a transformação da prática educacional, os entendimentos sobre educação, e os valores educacionais daqueles envolvidos no processo, e as estruturas sociais e institucionais as quais fornecem o esqueleto para sua ação. Nesse sentido, uma ciência da educação crítica não é uma pesquisa sobre ou a respeito de educação, ela é 
uma pesquisa na e para a educação (p. 156).

"Pesquisa" é a palavra chave quando ensino e currículo são tratados de um modo crítico e estratégico. Ainda de acordo com Carr e Kemmis (1986), "um tipo de investigação que ele sugere requer que professores se tornem figuras críticas na atividade de pesquisa" (p. 40). Um "projeto de pesquisa" não significa apenas "investigar atitude sobre o ensino e o currículo", mas também "um domínio específico de ação estratégica será selecionada para uma investigação mais sistemática e continuada" (p. 40). Como eles ainda afirmam, "quando professores adotam uma perspectiva de projeto, eles também criam oportunidades para aprender a partir de sua experiência e planejar sua própria aprendizagem" (p. 40). Desse modo:

[...] ele ou ela ajudam a estabelecer comunidades críticas de pesquisa no ensino, no currículo e na organização da escola, e administração de grupos dentro da escola, da escola como um todo ou entre escolas. Essa auto-reflexão crítica, empreendida em uma comunidade auto-crítica, usa comunicação como um meio para desenvolver um sentido de experiência comparada, para descobrir determinantes locais ou imediatos sobre a ação pela compreensão dos contextos dentro dos quais outros trabalham e convertendo experiência em discurso, usando a linguagem como auxílio para a análise e o desenvolvimento de um vocabulário crítico o qual fornece os termos para a reconstrução prática (CARR e KEMMIS: 1986, p. 40).

$\mathrm{Na}$ racionalidade crítica, o professor é visto como alguém que levanta problemas. Como se sabe, alguns modelos dentro da visão técnica e prática também concebem o professor como alguém que levanta problemas. Contudo, tais modelos não compartilham a mesma visão sobre essa concepção a respeito da natureza do trabalho docente. Os modelos técnicos têm uma concepção instrumental sobre o levantamento de problemas; os práticos têm uma perspectiva mais interpretativa e os modelos críticos têm uma visão política explícita sobre o assunto. De acordo com Shor (1992), o levantamento de problemas tem raiz no trabalho de John Dewey e Jean Piaget. Entretanto, foi Paulo Freire quem desenvolveu uma ideia política sobre tal concepção, por meio de seu método do "diálogo de levantamento de problemas", no qual "o professor é frequentemente definido como alguém que levanta problemas e dirige um diálogo crítico em sala de aula; levantamento de problema é um sinônimo de pedagogia" (p. 31). Nas palavras desse autor:

Como pedagogia e filosofia social, o levantamento de problemas enfatiza relações de poder em sala de aula, na instituição, na formação de critérios padronizados de conhecimento e na sociedade como um todo. Ela considera o contexto social e cultural da educação, perguntando como a subjetividade do estudante e suas condições econômicas afetam o processo de aprendizagem. A cultura do estudante bem como a desigualdade e a democracia são temas centrais para 
educadores "levantadores de problemas" quando eles examinam cuidadosamente o ambiente para a aprendizagem (SHOR: 1992, p. 31).

No modelo freiriano, o levantamento de problemas é concebido como "um processo mútuo para estudantes e professores questionarem o conhecimento existente, o poder e as condições" (p. 33). Assim, uma comunidade de professores-pesquisadores, com estudantes como coinvestigadores, estabelece um processo democrático e centrado no aluno, por meio do qual o currículo é construído "de baixo para cima" em vez de ser construído "de cima para baixo".

Existem no mínimo três modelos baseados na racionalidade crítica: o modelo sócio-reconstrucionista, o qual concebe o ensino e a aprendizagem como veículos para a promoção de uma maior igualdade, humanidade e justiça social na sala de aula, na escola e na sociedade (LISTON e ZEICHNER, 1991); o modelo emancipatório ou transgressivo, o qual concebe a educação como expressão de um ativismo político e imagina a sala de aula como um local de possibilidades, permitindo ao professor construir modos coletivos para ir além dos limites, para transgredir (HOOKS 1994); e o modelo ecológico crítico, no qual a pesquisa-ação é concebida como um meio para desnudar, interromper e interpretar desigualdades dentro da sociedade e, principalmente, para facilitar o processo de transformação social (CARSON e SUMARA, 1997).

Dependendo da concepção que se assume, a chamada "formação de professores para a justiça social" também poderia se apresentar como um modelo da racionalidade crítica de formação de educadoras/es. Porém, como veremos a seguir, essa discussão é permeada de armadilhas conceituais e precisa ser tratada com um pouco mais de cuidado.

\section{“FORMAC̣ÃO DE PROFESSORES PARA A JUSTIC̣A SOCIAL" VS. "FORMAC̣ÃO DE EDUCADORASIES POR MEIO DA TRANSFORMAC̣ÃO SOCIAL"}

Zeichner (2004), ao revisar a literatura especializada nos Estados Unidos dos últimos 75 anos (a partir do ano de publicação de seu artigo), afirma que a formação de professores para a justiça social tornou-se apenas um slogan que tem sido usado para descrever a orientação de muitos programas de formação docente no mundo. $\mathrm{O}$ autor argumenta que, assim como aconteceu com o termo "reflexão" nos anos 1980, nós chegamos a um ponto em que é difícil discernir, para além do refrão "justiça social", o que realmente acontece em um programa de formação de professores "para a justiça social". Embora as concepções e práticas que estão sob o "guarda-chuva" da formação de professores 
para a justiça social variem enormemente, Zeichner afirma que existe pouca discussão sobre essa variação na literatura da área.

Zeichner sugere que é necessário revelar o que há por detrás do slogan da formação de professores para a justiça social. O autor examina a variedade de modos como esse slogan tem sido concebido e implementado nos EUA, discute algumas contradições entre o discurso e a prática dos programas que adotaram esse slogan, bem como faz uma avaliação daquilo que se tem conseguido por meio dos esforços para se implantarem programas como esses.

A "justiça social” é um termo que tem sido usado por movimentos, organizações e pessoas progressistas há muito tempo e que tem sido recentemente cooptado e retoricamente adotado por instituições e indivíduos conservadores. Por exemplo, os chamados "neoliberais" têm retoricamente expressado o seu compromisso para a implantação da "justiça social" no mundo. Todavia, para os neoliberais, "justiça social" significa, na verdade, "a igualdade de oportunidades" para os "cidadãos" (também recorrentemente concebidos como "consumidores") competirem no mercado global. O fato de que a "oportunidade", a liberdade e a escolha estejam diminuindo cada vez mais em outras esferas de vida da maioria dos cidadãos-consumidores, sujeitas às demandas das necessidades das grandes corporações, não faz parte do discurso neoliberal sedutor.

Em nosso modo de pensar, ser comprometido com a justiça social é uma posição política que, diferente da perspectiva neoliberal, explicitamente se opõe ao status quo e procura promover mudanças profundas nas relações de poder existentes nos níveis pessoal, local, nacional e internacional. Opor-se ao status quo significa ser simultaneamente anticapitalista (contra a exploração de classe), antiimperialista (contra as velhas e novas formas de colonização econômica, simbólica e cultural), antipatriarcal (contra a desigualdade de gênero), antirracista (contra a opressão de raça e a chamada "supremacia branca"), anti-homofóbico (contra a discriminação por orientação sexual) e contra a exclusão social de pessoas com deficiência.

Mesmo procurando ser o mais claro e o mais explícito possível em relação ao significado do termo "justiça social”, seguindo a tradição freiriana, nós preferimos usar neste artigo o termo "transformação social". Embora isto possa ser visto como se nós estivéssemos criando uma falsa dicotomia. Na nossa visão, a ênfase na "transformação social" difere conceitualmente e politicamente da ênfase de vários programas educacionais, incluindo programas de formação de professoras/es, sobre a questão da "justiça social" e/ou da "inclusão social" - esta última tem sido mais usada em programas 
educacionais no Brasil. Nós acreditamos que um programa educacional e, mais especificamente, um programa de formação de professoras/ es comprometido em promover uma profunda transformação social é também necessariamente comprometido com a "justiça social" e com a "inclusão social". Porém, nós cremos que, ao usar o termo "transformação social", em vez de "justiça social" ou "inclusão social", poderíamos evitar a cooptação intencional do primeiro termo pela direita reacionária e, no caso do segundo termo, lembrar que, dependendo da perspectiva adotada, a "inclusão social" pode ser vista como um fim em si mesma, deixando sem questionamento as verdadeiras fontes das desigualdades sociais. Ou como defendeu Miguel Arroyo, na Introdução do livro Quando a diversidade questiona a formação docente (DINIZ-PEREIRA e LEÃO, 2008): devemos buscar compreender (e explicitar!) os processos históricos brutais que transformaram (e transformam) os diferentes em desiguais.

O pressuposto é que a sociedade capitalista (que também é patriarcal, racista, homofóbica e discriminatória) sustenta-se na exclusão. Nesse caso, a conquista de pequenos pacotes de "inclusão social" oude "justiçasocial" nãopode sercomemorada prematuramente e ingenuamente. Isto porque tal "inclusão" ou "justiça” é, na verdade, cooptada. Além de ser outorgada por aqueles que detêm o poder (os opressores) como um meio de minimizar certas tensões sociais e, consequentemente, manter os seus privilégios, tal "inclusão" ou "justiça" sempre acontece de maneira marginalizada e temporária. Em outras palavras, os sujeitos socialmente, racialmente, culturalmente e economicamente excluídos e segregados (os oprimidos) devem ser os agentes principais da transformação social. Eles devem ser capazes de conquistar, por meio de lutas sociais coletivas, a sua própria liberdade. Como Freire (2016) afirma "a liberdade, que é uma conquista, e não uma doação, exige uma permanente busca” (p. 68).

Além disso, defendemos romper com a perspectiva teleológica e propedêutica tanto da expressão "formação de professores para a justiça social" quanto da expressão "formação de professores para a transformação social" e adotar a expressão "formação de educadoras/ es por meio da transformação social" em que, tomando por base a experiência do Movimento dos Trabalhadores Sem Terra (MST) no Brasil, primeiro transforma-se a realidade e a condição indigna e desumana dos Sem Terra e, ao lutar pela manutenção e ampliação dessa transformação, já sendo sujeitos dela, forma-se/educa-se nesse processo.

Por fim, precisaríamos perguntar: como poderíamos converter programas de formação de professores mantidos por universidades e por instituições de ensino superior que, via de regra, são instituições 
conservadoras - porém, contraditórias -, em programas de formação de educadoras/es por meio da transformação social?

\section{PROGRAMAS DE FORMAC̣ÃO DE EDUCADORAS/ES POR MEIO DA TRANSFOR- MAÇÃO SOCIAL}

Não existe resposta simples para essa questão. Não é nossa intenção nesta parte do artigo fornecer uma receita de "como criar um programa de formação de educadoras/es por meio da transformação social".

Por um lado, se um programa de formação de professoras/ es tem um compromisso verdadeiro com a transformação social, aqueles que dele participam - estudantes (futuros professoras/ es), servidoras/es técnico-adminstrativos e servidoras/es docentes (formadoras/es de professores) - devem ser capazes de encontrar soluções para os seus problemas específicos e desenvolver uma proposta curricular com essa finalidade. Além disso, nós diríamos que essas possibilidades dependem do nível de autonomia que cada programa tem - o que, por sua vez, depende de uma luta constante para conquistar essa autonomia - a fim de convertê-los em programas de formação de educadoras/es por meio da transformação social.

Por outro lado, nós acreditamos que podemos aprender lições importantes a partir da experiência do Movimento dos Trabalhadores Sem Terra (MST), no Brasil, na década de 1990 e início dos anos 2000, sobre o desenvolvimento de programas de formação de educadoras/ es por meio da transformação social. Para Arroyo:

De alguma forma os movimentos sociais reeducam o pensamento educacional, a teoria pedagógica, a reconstrução histórica da Educação Básica. Um pensamento que tinha como tradição pensar essa história como apêndice da história oficial, das articulações do poder, das concessões das elites, das demandas do mercado. Seria de esperar que a reconstrução da história da democratização da escola básica popular na América Latina não esquecesse de que ela é inseparável da história social dos setores populares, de seus avanços na consciência dos direitos. (ARROYO, 2011 p. 245.)

$\mathrm{Na}$ nossa visão, um dos maiores desafios em desenvolver programas de formação de educadoras/es por meio da transformação social está justamente na dificuldade em construir parcerias com movimentos e organizações sociais e culturais progressistas que estão envolvidos na verdadeira transformação da sociedade. ${ }^{3}$ Dessa maneira, envolver-se diretamente em lutas concretas de transformação social seria uma característica essencial e insubstituível desse tipo de 
programa de formação de educadoras/es. Além disso, existem, no mínimo, outros quatro aspectos desse tipo de programa nos quais deveríamos também prestar bastante atenção.

Em primeiro lugar, é impossível pensar em desenvolver um programa de formação de educadoras/es por meio da transformação social se não tivermos um grupo de formadoras/es de professoras/es que realmente acreditam que "um outro mundo é possivel". Assim, é crucial que os formadoras/es de professoras/es envolvidas/os nesse programa compartilhem sonhos e um compromisso político com a transformação social. Em vez de uma preocupação apenas com suas carreiras individuais, essas/es formadoras/es de professoras/es deveriam demonstrar, por meio de sua praxis, um compromisso com esse programa, seus estudantes e o seu desenvolvimento como educadoras/es militantes. ${ }^{4}$

Além disso, por não existir uma receita ou uma fórmula mágica de como desenvolver um programa de formação de educadoras / es por meio da transformação social e de como desenvolver uma proposta curricular nessa direção, as/os formadoras/es de professoras/es envolvidas/os nesse programa devem ser capazes de criar espaços para refletir coletivamente e tomar decisões coletivas sobre o programa, bem como compartilhar e discutir suas práticas como formadoras/es de professoras/es e os desafios para a formação de educadoras/es militantes.

O segundo aspecto é a seleção das/os estudantes (futuras/os educadoras/es). Os programas tradicionais de formação de professores geralmente baseiam-se em critérios meramente acadêmicos para definir quem participará desses programas. Programas de formação de educadoras/es por meio da transformação social deveriam também levar em consideração as experiências que as/os candidatas/os trazem para os programas e a capacidade que elas/es têm para refletir sobre essas experiências - mesmo que essa reflexão seja ainda embrionária. Isto porque, como Freire (2000) argumenta, a reflexão "não pode ser puramente intelectual mas deve envolver necessariamente uma ação" (p. 47), esses programas deveriam privilegiar, então, candidatas/os que estão envolvidas/os em lutas sociais coletivas e, mais especificamente, em movimentos e organizações sociais e culturais progressistas.

Idealmente, as/os estudantes (futuras/os professoras/es) deveriam chegar no programa com, no mínimo, um sentimento de que existe alguma coisa essencialmente errada com a sociedade em termos de justiça e igualdade. Portanto, o programa deveria privilegiar candidatas/os mais vulneráveis socialmente (aquelas/es que vêm de famílias de classes populares ou trabalhadoras, independentemente do gênero, da raça e da orientação sexual; mulheres, pessoas de 
cor, homossexuais e pessoas com deficiência). O pressuposto é o seguinte: como seria mais fácil para as pessoas mais vulneráveis socialmente entenderem o princípio básico de que "existe alguma coisa fundamentalmente injusta na sociedade", ao privilegiar o acesso dessas pessoas ao ensino superior, nós já estaríamos ajudando a promover mudanças na sociedade. Candidatas/os vindos de situações sociais mais privilegiadas poderiam, obviamente, também ser aceitas/ os em programas de formação de educadoras/es por meio da transformação social, porém, elas/es deveriam ser capazes de mostrar que já iniciaram o processo freiriano de "morrer para renascer", mesmo que esse processo ainda seja embrionário. Nesse caso, autobiografias e entrevistas seriam instrumentos cruciais para o processo de seleção. ${ }^{5}$

Um terceiro aspecto importante é a participação ativa das/os estudantes (futuras/os professoras/es) nas tomadas de decisão sobre o currículo durante seus percursos nos programas de formação de educadoras/es por meio da transformação social. Embora o curso de formação inicial de professoras/es do MST, na década de 1990 e início dos anos 2000 fosse, pelo menos em termos da sua estrutura formal, parecido com os cursos tradicionais de formação de professoras/ es no Brasil, as/os estudantes (futuras/os professoras/es) eram muito ativos (as) e bastante dispostos a participar da construção do currículo. Elas/es queriam negociar cada passo do curso e recusaramse a aceitar um "pacote pronto", vindo de suas/seus formadoras/es de professoras/es ou da universidade. Seria essencial que o programa não apenas permitisse mas que encorajasse esse tipo de participação no desenvolvimento de seus currículos. Nesse sentido, o aspecto anterior (a seleção das/os participantes do programa) poderia também ajudar a fomentar a participação das/os estudantes no programa. Assim como no caso dos participantes dos cursos de formação inicial de professoras/es do MST nos anos 1990 e início dos anos 2000, as/os candidatas/os selecionadas/os nos programas de formação de educadoras/es por meio da transformação social também não deveriam aceitar "pacotes prontos" vindos dos programas.

Finalmente, também seria crucial prestar atenção nas experiências teórico-práticas dos estágios supervisionados que um programa de formação de educadoras/es por meio da transformação social oferece para as/os suas/seus participantes. De uma maneira ideal, seria importante selecionar escolas ${ }^{6}$ e outros locais para a realização do estágio em que as/os educadoras/es estejam envolvidas / os em lutas sociais coletivas e as/os professoras/es supervisoras/es e outras/os educadoras/es se autoidentifiquem como educadoras/ 
es militantes. Mais recentemente, defende-se também a participação ativa das comunidades no entorno das escolas nas ações de formação de educadoras/es (ver ZEICHNER, 2015).

Como afirmado anteriormente, é importante enfatizar que todos esses aspectos dependerão do nível de autonomia do programa para contratar livremente formadoras/es de professoras/es, usando também critérios políticos e ideológicos, em vez de critérios apenas acadêmicos - supostamente neutros, a fim de definir os critérios e os instrumentos para a seleção das/os estudantes, para permitir e encorajar as/os estudantes a participar ativamente na tomada de decisões sobre o currículo do programa, e, finalmente, selecionar locais de realização de estágios supervisionados mais progressistas para o desenvolvimento das experiências práticas das/os estudantes.

O programa de formação de professoras/es do Movimento dos Trabalhadores Sem Terra (MST), no Brasil, nos anos 1990 e início dos anos 2000, pode ser considerado um exemplo de iniciativa de preparação de profissionais da educação que se fundamenta na racionalidade crítica e se enquadra entre os modelos de formação de educadoras/es por meio da transformação social. Esse programa será brevemente apresentado e discutido no próximo item.

\section{O PROGRAMA DE FORMACฺ̃̃O DE EDUCADORAS/ES DO MST}

Entre as diferentes ações do MST na área educacional, a formação de professoras/es sempre foi, sem dúvida alguma, uma de suas prioridades. $\mathrm{Na}$ visão do Movimento, a formação de professoras/es não deve ser restrita ao acesso a um curso de preparação profissional. Na verdade, o MST considera como parte de seu programa de formação de educadoras/es várias estratégias e práticas educativas, e o acesso a um curso de formação profissional é apenas uma dessas estratégias e práticas. Em consonância com o seu projeto educacional, ${ }^{7}$ o programa de formação de educadoras/es do MST também é politicamente comprometido com uma estratégia mais ampla de transformação social. Aqui cabem algumas perguntas para refletirmos: qual o programa de formação de professoras/es, em nossas universidades e demais instituições de ensino superior, que "explicitamente" se compromete com a transformação social em nosso país? Caso isso aconteça, que implicações isso traz para o programa em questão? Que mudanças isso acarreta na prática dos formadores de professoras/es na sala de aula?

De acordo com Caldart (1997), eram três as principais dimensões 
do programa de formação de educadoras/es do MST, na década de 1990:

- Preparação profissional e técnica: para se promover conhecimentos científicos e práticos, habilidades, comportamentos, cuidados e atitudes éticas sobre o pensar e o fazer a educação, com atenção especial às necessidades das áreas rurais, à reforma agrária e à justiça social;

- Preparação política: para o desenvolvimento de uma consciência histórica e de classe que ajude os educadores a compreender que as suas práticas estão ligadas a um propósito mais amplo de transformação social;

- Preparação cultural: para se enfatizar a necessidade dos educadores se organizarem criativamente e construírem uma cultura de cooperação e de solidariedade.

Como mencionado anteriormente, é impossível separar os objetivos mais gerais do Movimento, em termos da sua luta pela reforma agrária e da promoção da justiça social, de seus objetivos educacionais. Mesmo a dimensão técnica e profissional do programa de formação de professoras/es do MST, na década de 1990 e início dos anos 2000, tinha uma clara conexão com seus propósitos políticos mais amplos.

Dessa maneira, o MST pretendia construir, por meio de seu programa de formação de educadoras/es, uma identidade docente que não é neutra. Pelo contrário, tratava-se de uma identidade profissional que estava explicitamente comprometida com a promoção da justiça social. Em vez de reforçar o isolamento e o individualismo na docência, essa identidade era construída por meio de experiências de solidariedade e trabalho coletivo. Nas palavras de Paulo Freire:

\footnotetext{
Ninguém pode estar no mundo, com o mundo e com os outros de forma neutra. Não posso estar no mundo de luvas nas mãos constatando apenas. A acomodação em mim é apenas caminho para a inserção, que implica decisão, escolha, intervenção na realidade. Há perguntas a serem feitas insistentemente por todos nós e que nos fazem ver a impossibilidade de estudar por estudar. De estudar descomprometidamente como se misteriosamente, de repente, nada tivéssemos que ver com o mundo, um lá fora e distante mundo, alheado de nós e nós dele. (FREIRE: 2001, p. 75.)
}

No programa de formação de educadoras/es do MST, na década de 1990 e início dos anos 2000, existia uma multiplicidade de iniciativas que aconteciam em nível local, regional, estadual e nacional e que representavam espaços fundamentais para o crescimento político e pedagógico dos professores e para a aquisição do conhecimento a ser socializado em sala de aula (BELTRAME, 2000). 
Como será discutido a seguir, existem muitas estratégias e atividades que o MST também considerava como parte de seu programa de formação de professoras/es, na década de 1990 e início dos anos 2000. Por exemplo, o engajamento das/os professoras/es nas lutas coletivas do Movimento e sua participação nos coletivos de educação; a sistematização da prática pedagógica; a participação na produção coletiva e na socialização de materiais didáticos e pedagógicos para serem usados nas escolas de assentamentos e acampamentos; a presença e a participação em reuniões, seminários, oficinas e cursos de curta duração, entre outras.

\section{O PROGRAMA DE “FORMAC̣ÃO INICIAL" DE PROFESSORAS/ES DO MST}

Na década de 1990 e início dos anos 2000, existiam dois tipos de cursos que faziam parte do programa de "formação inicial" 8 de professoras/es no MST: o "Magistério", em nível de ensino médio; e a "Pedagogia da Terra", em nível superior. Ambos eram responsáveis pela preparação e certificação de professoras/es do ensino fundamental que atuariam, preferencialmente, em escolas de assentamentos e acampamentos do MST.

O Magistério, criado em 1990, deixou de existir em razão das alterações na legislação educacional brasileira que passou a recomendar, a partir de 1996, o ensino superior para aqueles que atuariam, como professoras/es, nas salas de aula do país. Seu tempo de duração era, em média, dois anos e meio.

O primeiro programa de formação de professoras/es, em nível superior, do MST - Pedagogia da Terra - foi criado em 1998, por meio de uma parceria entre o Movimento e a Universidade do Vale do Rio dos Sinos (UNISINOS), no Rio Grande do Sul. A partir dessa experiência, multiplicaram-se novas parcerias com outras instituições de ensino superior brasileiras em diferentes estados do país.

Esses dois programas eram divididos em duas partes: o "Tempo Escola" - correspondia ao período de tempo em que as/os futuras/ os professoras/es se envolviam em discussões acadêmicas e políticas sobre educação e ensino-aprendizagem, frequentando uma série de cursos acadêmicos, participando em discussões políticas e estudando os materiais produzidos pelo Movimento; e o "Tempo Comunidade" correspondia ao período de tempo em que as/os futuras/os professoras / es permaneciam nas escolas dos acampamentos ou dos assentamentos e se envolviam em um conjunto de atividades na própria comunidade.

De acordo com Caldart (1997), o “Tempo Escola" era dividido 
em outros três "tempos":

- Os "tempos" relacionados ao desenvolvimento do currículo oficial do programa, por meio da participação em aulas, seminários para estudo e discussão de temas específicos, leituras individuais e coletivas, escrita de um diário e atividades de educação física;

- Os "tempos" relacionados à autogestão do programa e do desenvolvimento de habilidades específicas para tal fim: por exemplo, trabalhar em comissões criadas para autogerenciar o programa; participar de oficinas e cursos de curta-duração para desenvolver habilidades específicas necessárias ao autogerenciamento do programa; participar de reuniões e assembleias como parte da gestão coletiva do programa;

- Os "tempos" relacionados à formação cultural do grupo: celebração da mística; atividades de entretenimento individuais e coletivas; manter-se informado por meio da imprensa; realização de festas; visitas orientadas; oficinas artísticas, entre outras.

De maneira semelhante ao que acontece com o "Tempo Escola", o "Tempo Comunidade" também era dividido em outros "tempos" menores:

- "Tempo" para continuar o trabalho que os professores desenvolvem em suas comunidades, mas, desta vez, refletindo sobre suas ações pedagógicas e fazendo anotações sobre suas práticas, por meio da escrita de um diário;

- "Tempo" para colocar em prática diferentes atividades pedagógicas, vivenciando desafios metodológicos em cada uma das frentes educacionais do MST;

- "Tempo" para desenvolver uma investigação que culmina em um Trabalho de Pesquisa-Ação, o TPA. As/Os futuras / os professoras/es escrevem, então, uma Monografia sobre suas pesquisas e apresentam os seus resultados para as/os formadoras/es e colegas do programa;

- "Tempo" para desenvolverem atividades adicionais de envolvimento com a comunidade para aprofundar seus conhecimentos sobre a realidade mais ampla do assentamento ou do acampamento e cultivar "uma ética de engajamento, compromisso e solidariedade";

- "Tempo" para aplicar a lógica da autogestão coletiva que 
eles experenciaram durante o "Tempo Escola" em suas instituições de ensino fundamental (CALDART, 1997).

Além desses dois cursos de "formação inicial", o "Magistério" e a "Pedagogia da Terra", existia ainda uma série de iniciativas para o acompanhamento das/os educadoras/es que atuavam nas escolas de assentamento e acampamento do MST. Essas iniciativas constituíam-se no programa de formação continuada de professoras/es do Movimento.

\section{O PROGRAMA DE FORMAC̣ÃO CONTINUADA DE PROFESSORAS/ES DO MST}

Como parte de seu programa de formação de professoras/es, o MST desenvolvia também um conjunto de atividades para aqueles que ensinavam nas escolas de assentamentos e acampamentos.

Essas/es professoras/es recebiam regularmente materiais pedagógicos, os quais eram produzidos pelo próprio MST, levando em consideração as experiências de suas/seus educadoras/es e os conhecimentos de profissionais de áreas específicas e das lideranças do Movimento. A linguagem utilizada nesses materiais era muito acessível às/aos professoras/es e aos demais membros da comunidade. As/Os professoras/es deveriam discutir esses materiais nos coletivos locais de educação. Geralmente, os materiais eram muito úteis para uma melhor compreensão dos propósitos políticos e educacionais do MST.

A participação das/os professoras/es nos coletivos locais de educação era considerada umas das atividades mais eficazes em termos de formação continuada. Uma vez por semana, as/os docentes estudavam os materiais sobre educação, discutiam coletivamente o currículo da escola e desenvolviam os planos de aula. Estudantes e demais membros da comunidade também participavam desses coletivos. Uma das entrevistadas da pesquisa desenvolvida por um dos autores deste artigo ${ }^{9}$ ressaltou esse aspecto da formação continuada:

\footnotetext{
"Nós trabalhamos muito duro para organizar esses coletivos... assim como para que se crie a necessidade dos professores continuarem estudando e reconhecerem a importância dos coletivos pedagógicos...” (Cleonice) $)^{10}$
}

Contudo, não era suficiente "apenas" organizar os coletivos locais e enviar os materiais produzidos pelo MST para as escolas. As/Os professoras/es solicitavam e recebiam apoio em termos da discussão e análise desses materiais. Dessa maneira, o suporte pedagógico às/aos professoras/es era também considerado parte do programa de formação continuada de educadoras/es do Movimento. 
Esse trabalho era desenvolvido pelos setores regionais e estaduais de educação do MST (BELTRAME, 2000).

Uma das estratégias para se fornecer tal apoio pedagógico às/aos professoras/es era a realização de oficinas de trabalho. Essas oficinas transformaram-se em espaços privilegiados para as/os professoras/es que ensinavam em diferentes escolas, de diferentes assentamentos ou acampamentos, socializarem e discutirem suas práticas e experiências. As atividades práticas eram enfatizadas nessas oficinas. Como não poderia deixar de ser, a celebração da mistica era outra atividade pedagógica desenvolvida durante as oficinas.

De acordo com Beltrame (2000), se por um lado é verdade que as atividades desenvolvidas durante as oficinas procuravam valorizar o conhecimento e a cultura das/os docentes, por outro, as/os formadoras/es, responsáveis pela coordenação das atividades durante as oficinas, também ofereciam elementos para ajudar as/os professoras/es a rever e melhorar suas práticas de ensino.

Outra atividade do programa de formação continuada de educadoras/es do MST era a participação em encontros regionais e estaduais de professoras/es que lecionavam em diferentes escolas de assentamentos e acampamentos do Movimento. Esses encontros aconteciam regularmente, durante todo um final de semana. Os integrantes do MST que participavam dos setores regionais e estaduais de educação ajudavam a organizar e coordenar esses eventos. Discussões sobre as práticas pedagógicas das/os professoras/es nas escolas de assentamento eram enfatizadas nesses encontros. Os participantes discutiam ainda temas como, por exemplo, as condições de vida nas zonas rurais brasileiras, o trabalho docente nas escolas do campo e a participação política no MST.

É importante ressaltar que, durante esses encontros, as/os educadoras/es não se limitavam a discutir suas práticas docentes e outros temas pedagógicos ou mesmo a participar de oficinas para aprender diferentes atividades a serem desenvolvidas em suas salas de aula. Além disso, como uma das entrevistadas da pesquisa mencionada anteriormente enfatizou, e não isento de uma intencionalidade formativa, elas/es também faziam "coisas corriqueiras e comuns".

"Nós organizamos esses encontros como nós fazemos em qualquer outro evento educacional do MST. Os professores devem lavar os pratos, limpar os quartos, a área externa... Nós organizamos o encontro dividindo as pessoas em núcleos ou brigadas e distribuindo as atividades... Isso é algo muito importante para a convivência desse grupo. É por meio dessa experiência que eles vão aprender a ouvir mais uns aos outros, a respeitar mais a opinião do outro, a trabalhar coletivamente... Assim, mais do que falar sobre a Pedagogia do MST, o que nós 
fazemos durante esses encontros é dar a eles a oportunidade de vivenciar a Pedagogia do MST... Para nós, é essencial não apenas "o saber como fazer" mas também e principalmente 'o saber como ser'...” (Cleonice).

Elas/es ainda celebravam a "mística", planejavam as ações políticas que estavam previamente marcadas, discutiam como organizar eventos em suas comunidades locais e elegiam representantes para participarem de outros encontros de educação do Movimento, em nível estadual e nacional.

Os principais propósitos dos encontros nacionais e estaduais de educação do MST eram: propiciar espaços para a socialização de experiências; possibilitar aos educadores o desenvolvimento de uma visão crítica por meio do distanciamento da sua realidade escolar e, ao mesmo tempo, incentivar as/os professoras/es a transformarem suas práticas. Segundo Beltrame (2000), esses eventos contavam com a participação de um número expressivo de educadoras/es e constituíam-se em espaços importantes para reflexão e redefinição de suas práticas educativas.

Como mencionado anteriormente, o programa de formação de educadoras/es do MST, na década de 1990 e início dos anos 2000, não se reduzia ao acesso a um dos cursos de preparação profissional do Movimento e à participação nas atividades de acompanhamento nas salas de aula. Como será tratado a seguir, havia também outras estratégias que eram consideradas importantes para a formação dos professoras/es das escolas de assentamento e acampamento.

\section{OUTRAS ESTRATÉGIAS DE FORMACุÃO DE PROFESSORAS/ES DO MST}

A participação política das/os professoras/es em diferentes espaços sociais em suas comunidades locais era uma estratégia muito importante do programa de formação docente do MST, na década de 1990 e início dos anos 2000. O Movimento considerava crucial o envolvimento das/os professoras/es em manifestações políticas, passeatas, marchas, ocupações de terra e de prédios públicos.

Participar de diferentes eventos políticos no MST era, então, parte do programa de formação de educadoras/es do Movimento, na década de 1990 e início dos anos 2000. Essa participação em acontecimentos políticos era muito importante, pois reforçava, nas/ os professoras/es e educadoras/es, o sentimento de pertencimento ao Movimento (BELTRAME, 2000). As entrevistadas da pesquisa mencionada anteriormente confirmaram essa ideia do maior 
envolvimento das/os educadoras/es com o Movimento como uma estratégia importantíssima de formação:

“O Movimento é um sujeito pedagógico. O Movimento, por si só, já é um educador. Não existe nada mais formativo que o próprio envolvimento com as lutas do Movimento. Nós normalmente dizemos: ‘O coletivo educa'...” (Lúcia).

Sobre outras estratégias de formação de educadoras/es do MST, as entrevistadas também mencionaram os encontros dos "SemTerrinha" - que envolviam crianças, filhos de assentados e acampados, de oito a catorze anos - e os encontros da juventude do MST - em que participavam adolescentes assentados ou acampados de quinze a dezessete anos. Durante esses eventos, as crianças e os adolescentes estudavam e discutiam valores humanistas e socialistas, aprendiam sobre seus direitos constitucionais e debatiam problemas vividos em suas comunidades. Depois de três ou quatro dias discutindo esses temas, as crianças e os adolescentes levavam essas discussões para suas comunidades e escolas.

Segundo as entrevistadas da pesquisa mencionada anteriomente, as crianças e os jovens que participavam desses encontros tornavam-se mais críticos e questionadores e, muitas vezes, desafiavam suas/seus professoras/es e diretoras/es, exigindo delas/es espaços nas escolas para a discussão dos assuntos lá tratados. As participantes da pesquisa mencionada anteriormente acreditavam que esse tipo de comportamento crítico e questionador das crianças e dos adolescentes tinha também um impacto em termos da formação docente.

Portanto, são muitas as lições que podemos aprender com as experiências do Movimento dos Trabalhadores Rurais Sem Terra (MST), da década de 1990 e início dos anos 2000, para desenvolver em nossas instituições programas de formação de educadoras/es por meio da transformação social e baseados na racionalidade crítica.

\section{CONSIDERAÇÕES FINAIS}

O que procuramos fazer neste artigo foi apresentar e defender a racionalidade crítica na formação de educadoras/es como alternativa às chamadas visões técnica e prática na preparação de novas/os professoras/es da educação básica. Em seguida, desenvolvemos uma discussão teórica e conceitual sobre as diferenças entre os termos "formação de professores para a justiça social" e "formação de educadoras/es por meio da transformação social". A partir daí, baseados na experiência concreta do Movimento dos 
Trabalhadores Sem Terra (MST), no Brasil, na década de 1990 e no início dos anos 2000, discutimos algumas características que não podem faltar em programas de formação de educadoras/es por meio da transformação social.

Por fim, na Introdução do livro de um dos autores deste artigo (DINIZ-PEREIRA, 2013), Kenneth Zeichner, Professor Emérito da Universidade do Estado de Wisconsin, em Madison, enfatizou a enorme diferença entre a experiência do MST no Brasil e aquilo que, nos Estados Unidos, denomina-se "programas de formação de professores para a justiça social" em que, na verdade, na maioria das vezes, apenas discutem-se temas relacionados à justiça social mas, raramente, associam-se efetivamente a ações concretas que lutam contra as desigualdades e injustiças presentes em nossas sociedades. Esse é o grande diferencial da experiência do MST e que, reconheçamos ou não, nos deixam importantes lições a serem aprendidas.

Em tempos em que os movimentos sociais progressistas do nosso país são intencionalmente e injustamente criminalizados, chamados irresponsavelmente de "organizações terroristas", e em que a "ideologia" (sic) do Patrono da Educação brasileira, Paulo Freire, pretende ser "expurgada" 11 dos currículos de nossas escolas e de nossas instituições de formação de educadoras/es, reforça-se a importância de uma discussão como esta do "tema gerador" central do $2^{\circ}$ Congresso Internacional Paulo Freire: O Legado Global e que também abordamos brevemente e de maneira incompleta em nosso artigo.

\section{REFERÊNCIAS}

APPLE, M. W.; BEAN, J. A. (org.). Democratic schools. Alexandria: ASCD, 1995.

ARROYO, Miguel. Miguel Arroyo: educador em diálogo com nosso tempo/textos selecionados de Miguel Arroyo; organização Paulo Henrique de Queiroz Nogueira, Shirley Aparecida de Miranda. --Belo Horizonte: Autêntica, 2011. -- (Coleção Perfis da Educação, 5)

BELTRAME, S. A. B. MST, professores e professoras: Sujeitos em movimento. Tese de Doutorado, São Paulo: Universidade de São Paulo, 2000.

CALDART, R. S. Pedagogia do Movimento Sem Terra. Petrópolis: Vozes, 2000.

CALDART, R. S. Educação em movimento: Formação de educadoras e educadores no MST. Petrópolis: Vozes, 1997.

CARR, W.; KEMMIS, S. Becoming critical: education, knowledge and action research. London: The Falmer Press, 1986. 
CARSON, T. R.; SUMARA, D. (org.). Action research as a living practice. New York: Peter Lang, 1997.

DE TOMMASI, L.; WARDE, M.; HADDAD, S. (org.). O Banco Mundial e as políticas educacionais. São Paulo: Cortez Editora, 1996.

DINIZ-PEREIRA, J. E. A formação acadêmico-profissional: Compartilhando responsabilidades entre as universidades e escolas. Trajetórias e processos de ensinar e aprender: didática e formação de professores. In: ENDIPE, 14, Pontifícia Universidade Católica do Rio Grande do Sul (PUCRS), Porto Alegre, Anais..., Porto Alegre, 2008.

DINIZ-PEREIRA, J. E. How the Dreamers are Born: struggles for social justice and the identity construction of activist educators in Brazil. New York: Peter Lang, 2013.

DINIZ-PEREIRA, J. E.; LEÃO, G. (org.). Quando a diversidade interroga a formação docente. Belo Horizonte: Autêntica, 2008.

ELLIOT, J. Action Research for Educational Change. Buckingham: Open University Press, 1991.

FREIRE, P. 2016. Pedagogia do oprimido. 60º ed. - Rio de Janeiro: Paz e Terra, 2016.

FREIRE, P. Pedagogia da autonomia: saberes necessários à prática educativa. São Paulo, Paz e Terra, 2011.

HOOKS, B. Teaching to transgress: education as the practice of freedom. New York: Routledge, 1994.

LISTON, D.; ZEICHNER, K. M. Teacher Education and the Social Conditions of Schooling. New York: Routledge, 1991.

RODGERS, C. "The Turning of One's Soul" - Learning to Teach for Social Justice: The Putney Graduate School of Teacher Education, Teachers College Record, vol. 108, n. 7, pp. 1266-1295, 2006.

SCHÖN, D. The reflective practitioner. New York: Basic Books, 1983.

SHOR, I. e FREIRE, P. A pedagogy for liberation: Dialogues on transforming Education. Wesport/London: Bergin \& Garvey, 1987.

\section{NOTAS}

${ }^{1}$ Conscientes do papel que a língua pode ter na reprodução de discriminações de gênero, adotaremos, ao longo deste artigo, um padrão diferente daquele usado na "norma culta", que adota o masculino como norma. Todas as vezes que nos referirmos aos profissionais da educação básica, em que as mulheres são nitidamente a maioria, partiremos do feminino e faremos a diferenciação do masculino: educadoras/es; professoras/es.

${ }^{2}$ Para um maior aprofundamento sobre o tema, sugerimos a leitura do livro: O Banco Mundial e as políticas educacionais. Lívia De Tommasi, Miriam Warde e Sérgio Haddad (orgs). São Paulo: Cortez Editora, 1996. 


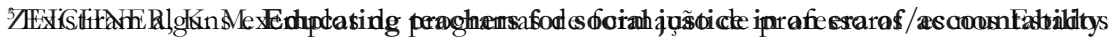

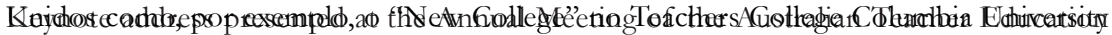

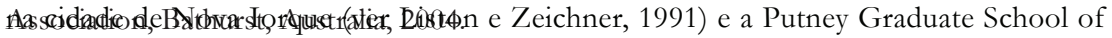
Teacher Education (ver Rodgers, 2006) que mantinham ligações com movimentos sociais

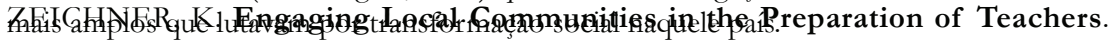
Kappa Delta Pi Record, vol. 51, n. 3, pp. 118-120, 2015.

${ }^{4}$ No livro How the Dreamers are Born (DINIZ-PEREIRA, 2013), um dos autores deste artigo usou o termo "educadores ativistas" em vez de "educadores militantes". Após 11 de setembro de 2001, o termo "militante" foi frequentemente utilizado pelos principais meios de comunicação nos EUA como sinônimo de "terrorista". Assim, para evitar qualquer malentendido sobre o conteúdo do livro, esse autor decidiu usar o termo "ativista" em vez de "militante". Porém, no Brasil, o termo "militante" ainda não tem a mesma conotação negativa como tem nos Estados Unidos. Em Português do Brasil, a palavra "militante" é geralmente entendida como alguém que participa ativamente na luta por justiça social. Paulo Freire, em sua conversa com Ira Shor, preferiu também usar o termo "militante" em vez de "ativista" para caracterizar os chamados "educadores libertadores". Ele disse: "educadores libertadores [...] devem tornar-se militantes no significado político dessa palavra [...]. Algo mais do que 'ativista'. Um militante é um ativista crítico" (SHOR e FREIRE, 1987, p. 50).

${ }^{5}$ Uma das primeiras atividades de programas de formação de educadoras/es por meio da transformação social deveria ser promover a análise crítica e a reflexão coletiva das experiências das/os participantes desses programas, usando as autobiografias delas/es visando a construção nelas/es de um sentimento de indignação contra as injustiças econômicas e sociais.

${ }^{6}$ De um modo ideal, os programas de formação de educadoras/es por meio da transformação social deveriam favorecer o trabalho com "escolas democráticas" como as descritas e analisadas no livro organizado por Apple e Bean (1995) ou, por meio do estabelecimento de parcerias com escolas públicas, ajudá-las para que elas mesmas tornem-se mais democráticas e comprometidas com a transformação social.

${ }^{7}$ Para uma melhor compreensão do programa de formação de professores do MST é imprescindível que se conheça também o seu projeto educacional. Aliás, como se sabe, as ações do Movimento não são isoladas. O programa de formação se insere no projeto educacional e este, por sua vez, articula-se com objetivos de luta mais amplos do próprio MST. Por isso, a leitura do livro de Roseli Caldart, Pedagogia do Movimento Sem Terra, torna-se obrigatória (ver CALDART, 2000).

${ }^{8}$ Em publicações anteriores, um dos autores apresentou uma série de motivos para não se utilizar o termo "formação inicial" em textos sobre formação de professoras/es (ver DINIZ-PEREIRA, 2008). Aqui esse termo foi mantido - mas sempre entre aspas - porque era a maneira como o próprio Movimento se referia aos seus cursos de preparação de profissionais da educação.

${ }^{9}$ Trata-se da pesquisa de doutorado realizada por um dos autores deste artigo na Universidade do Estado de Wisconsin, em Madison, nos Estados Unidos, entre 2000 e 2004 e que, posteriormente, foi publicada em forma de livro (ver DINIZ-PEREIRA, 2013).

${ }^{10} \mathrm{Na}$ pesquisa mencionada, seguindo orientações metodológicas e procedimentos éticos, o autor preferiu utilizar pseudônimos para preservar a identidade pessoal das entrevistadas.

${ }^{11}$ O verbo "expurgar" foi usado no Plano de Governo "BRASIL ACIMA DE TUDO. DEUS ACIMA DE TODOS” para se referir à "ideologia Paulo Freire”. (disponível em www.tse.jus.br) 
Submetido: 04/12/2018

Aprovado: 29/01/2019

Contato:

Universidade Federal de Minas Gerais (UFMG) Campus Pampulha

Faculdade de Educação Avenida Antônio Carlos, 6.627

Belo Horizonte $|\mathrm{MG}|$ Brasil 